\title{
Programme Profiles and the Reform of Higher Education in Europe: The Role of Tuning Europe
}

\author{
Luigi F. Donà dalle Rose and Guy Haug
}

\begin{abstract}
This article provides an overview of the profiling of higher education programmes in Europe as part of the overall process of higher education reform in Europe over the past decade (2000-2012) and of the role of Tuning in this process. The article starts with a recall of the architecture and objectives of the change process, based on the interplay between the intergovernmental Bologna process (with a main focus on structural change), the European Union's parallel Agenda for the Modernisation of Higher Education (with a focus on policy change for the Union's main objectives: growth and jobs, mobility, recognition and attractiveness) and Tuning. The second part of the article provides some data about and examples of the method and importance of Tuning in stimulating and shaping the renovation of higher education programmes, with a focus on Tuning's initial geographical area (Europe) and a glimpse to other continents, in line with Europe's need to build up the visibility and attractiveness of its universities in the rest of the world. The final section is a retrospective and analytical reflection about the impact of Tuning on some key dimensions of the agenda for the modernisation of higher education in Europe; while acknowledging that the Tuning method and principles have not always been fully understood by higher education as well as governmental institutions, Tuning has made an outstanding contribution to such key aspects as the relevance, comparability and quality of programmes, the development of quality assurance and accreditation policies and agencies and the recognition of qualifications - both within Europe and with partner countries in other parts of the world.
\end{abstract}

Keywords: Bologna Process; Competences; Curriculum Development; Employability; Europe; Higher Education Reform; Learning Outcomes; Modernisation of Higher Education; Programme Profiling; Quality Assurance; Tuning.

Tuning is one of several processes that have contributed to transforming higher education in Europe since the turn of the Millennium, in particular with respect to curricular renovation - a major requirement of both the panEuropean Bologna process and the EU's Agenda for the Modernisation of Higher Education. 


\section{The interplay between Bologna, Lisbon and Tuning}

\section{The Bologna Process}

In the wake of the Sorbonne Declaration that preceded it by one year, the Bologna Declaration emerged in 1999 with the ambition to set-up a coherent and attractive European Higher Education Area (EHEA). Its initial impetus came from the acknowledgment of need to address three main issues: the negative consequences of the fragmentation of European higher education into largely incompatible and illegible national systems; the worrying mismatch between what higher education is delivering and the changing needs of Europe's labour market; and the diminishing competitiveness of European higher education (and research) in the world.

The main thrust of the Bologna Process was to be on structural reforms converging towards a set of common features: a degree structure based on a common framework of reference for the first (bachelor-type), second (master-type) and third (doctoral-type) level of qualifications, ECTScompatible systems for the accumulation and transfer of credits, generalisation of the Diploma Supplement and more numerous joint/double degree courses, setting up of quality assurance systems with some kind of compatibility and articulation at the European level.

These structural changes were nonetheless expected to achieve more profound transformations:

- To foster more and easier mobility: lessons learnt from over 10 years of experience with the Erasmus programme showed both the power of large-scale mobility as a lever for change and the huge obstacle to mobility stemming from the fundamental incompatibility of the various national systems.

- To achieve more relevance of higher education to social and economic needs: concern about the "employability" of graduates has been maybe the most common feature between all signatory countries, mainly with respect to their domestic labour market, but also to the (single) European labour market; the capacity and the right of citizens to work anywhere in the EU - which is one of the pillars of European integration - can only become a reality if their qualifications are of sufficient quality and relevance and are legible and trusted beyond their national boundaries - which calls for more transparency and for compatible quality seals. At the same time, after a decade of largescale mobility and cooperation, authorities became more aware of the pockets of inefficiency in their national systems (e.g. in the form of over-long studies, high dropout and failure rates, high graduate 
unemployment or negative incentives to institutional effectiveness) and found out about better practice in other countries; these lessons from mobility and comparability provided renewed impetus for change/improvement in legislations, programmes and systems.

- To re-establish the attractiveness of European higher education in the world: Bologna spread the awareness that European higher education was not easily legible - neither in Europe nor a fortiori elsewhere in the world - and had lost (at least some) of its former attractiveness. This provided a strong impetus for remedial measures in many countries.

It was therefore expected that with Bologna most - if not all - universities in Europe would bring their existing degree structure in line with the main levels of First Degree (often Bachelor), Master and Doctorate and would seize the opportunity to revisit the architecture, content and teaching-learning methodology of their programmes, with a view to enhancing such aspects as employability, internationality, flexibility, attractiveness, access to lifelong learners, etc.

\section{The EU's agenda for the Modernisation of Higher Education}

This agenda was launched in 2002 as a strand of the "Lisbon Strategy" and has later been extended as one of the pillars of "Europe 2020", with a view to contributing to the Union's macro-strategy for growth, jobs and social integration in the knowledge era; as a result, the Bologna call for structural change has been intertwined with the EU's call for higher education policies "in a lifelong learning and a worldwide perspective".

Contrary to Bologna itself, the EU's agenda for higher education was to focus mainly on policy measures converging towards the Union's main goals, in such areas as system and institutional governance and funding, institutional and programme diversification, quality and relevance of studies and research-innovation, skills development for jobs and growth, quality assurance for mobility and the attractiveness of Europe as a destination for students, scholars and researchers from the rest of the world. Several of these policy areas, the reforms needed are also those promoted, from a different viewpoint, by the Bologna process, in particular with respect to the redefinition of study programmes and teaching/learning methods.

The main European Commission Communications that shaped the Agenda for the Modernisation of Higher Education ${ }^{1}$ gradually defined the

${ }^{1}$ In particular: Commission of the European Communities, "Mobilising the Brainpower of Europe: Enabling Universities to Make Their Full Contribution to the Lisbon Strategy," 
change needed in order to allow universities to make their full contribution to the Lisbon goals called for:

- an alignment of the all higher education qualifications with the four corresponding levels of the European Qualifications Framework (EQF);

- the definition of qualifications in terms of skills and competencies, having regard to the needs and capacities of the local and global labour market;

- greater efficiency of the learning process, with more flexible curricula, customised attention (tutoring) to the needs, difficulties and progress of each individual learner, formative evaluation, varied pedagogical approaches, recognition of prior learning, etc.;

- and the profiling of programmes with a view to diversifying the educational "menu" available to traditional and non-traditional learners and stimulating educational innovation.

This change agenda is largely an endorsement - or reinforcement within the EU context and drawing on EU processes and resources, of the curricular reform already advocated by the Bologna Process. It may also be seen as an acknowledgement that the achievement of the EU's macrostrategic goals hinges on the effective implementation of the Bologna reforms in higher education, in particular with respect to "renovation" and "profiling of the study programmes leading to the various types and levels of "qualifications". This intertwining of the Bologna and Lisbon agendas for change in higher education has resulted in their cross-fertilisation and has enhanced their global impact, in particular in such areas as curricular change, quality assurance or the recognition of qualifications within the EU as well as in the broader EHEA or in the rest of the world.

\section{Tuning within the context of higher education reforms in Europe}

Tuning, proceeding from the same awareness of the need for change in European higher education, started simultaneously and developed in parallel with the main underlying change processes (Bologna and Lisbon). Yet, its main focus has been on the re-development of teaching-learning programmes,

Communication from the Commission, COM (2005) 152 final, 12. Brussels: European Union, 2005; Commission of the European Communities, "Delivering on the Modernisation Agenda for Universities: Education, Research, and Innovation," Communication from the Commission, COM(2006) 208 final. Brussels: European Union, 2006. 
in the perspective of lifelong learning and with a view to the skills/ competencies (targeted Learning Outcomes) that students need to acquire in each main area of qualification.

This relies on, and calls for a very complex, difficult, Copernican revolution, since it implies a profound change in the purpose of higher education (equipping students with the right competences rather than acquiring all knowledge in a discipline), the design of the teaching-learning process (which needs to become student-centred rather than teacher-centred) and role and attitude of teachers, learners and programme managers. Hence, the call to reform higher education programmes became, at the same time, more "complicated" and more concrete. The need to realign programmes with the agreed learning objectives and qualification levels, to define them in terms of ECTS credits and gear them more towards "employability" and "Europe" (as required by Bologna and Lisbon) was complemented by the Tuning "approach", in two main ways: it allowed a first group of higher education professors to gain a more tangible understanding of the sense and scope of the reforms to be introduced, and it brought the debate to the level of the main disciplinary areas (or rather "qualification areas"). Through this dual contribution, Tuning has paved the way towards "real" change at the heart of the educational processes and communities.

Hence, it seems clear that while Tuning might not have existed in Europe without the supportive context of Bologna and Lisbon, ${ }^{2}$ there is little doubt that the impact of Bologna and Lisbon on the renovation of curricula and methods has been seriously strengthened thanks to Tuning.

\section{Tuning at work: profiling programmes in European higher education}

Tuning started in September 1999 as a project called Tuning Educational Structures in Europe and aimed at animating the process of curricular change at grass-root level in European higher education over the forthcoming years. It has drawn from the beginning on the new dynamics of the recently adopted Bologna Declaration (June 1999). A second thrust came from the already mentioned Copernican change in the learning / teaching methodologies from input-centred teaching to student and outcome-centred learning; this change was on-going since years at the lower levels of education; when transferred to the HE level, it raised considerably the attention paid to the real potential

${ }^{2}$ Nevertheless, Tuning - once born in Europe - has existed in other parts of the world without similar supporting contexts. 
and needs of the job market: in those days, common criticism referred to the mismatch between higher education and the job market, and to the overeducation of graduates with respect to the job market's needs.

The Tuning Project soon became a "process" in itself. Through TuningEurope, academics from over 150 Higher Education Institutes (HEIs) delivered important findings, which later were to inspire much of the rest of the world throughout similar processes. Tuning Europe was designed and implemented "by and for universities" and led to the development of an operational methodology for the design of degree programmes in specific thematic areas within the framework of the emerging common educational space in Europe. It became therefore known as the universities' response to the Bologna challenges put to them by their governments. The process was keen to respect the diversity of HE systems and institutions and their right to design their own programmes in an autonomous way: it was never meant to be prescriptive - even though it may sometimes have been misinterpreted as providing "model" programmes to be replicated. A pillar of the process has been the stress put on data sharing, joint analyses and dialogue - among academics, between academics and students/ graduates, among institutions, between institutions and current/potential employers, etc.

From its start Tuning Europe evolved through projects, which produced deliverables that would later be available as operational tools for academic institutions at large - not just for those involved in their actual development. It linked to, or affected higher education activities in several different ways.

\section{Common tools for the profiling of educational programmes}

Tuning started at grass root level (i.e. among normal academic staff) as an effort to define a common terminology and common concepts for the planning, maintenance and description of programmes. This common language refers to the competencies needed by students for their personal life and for the job market, ${ }^{3}$ which they need to have acquired at the time of course completion and to demonstrate through the assessment of the appropriate "Learning Outcomes".

Subsequently, it led to the actual use of these concepts throughout the academic community as tools for the definition of specific programmes, i.e. for their profiling in the institutional and global context.

3 The term "job market" is used here in its most general significance, including for instance, self-employment or research positions in the HEI themselves. 
The Tuning terminology soon came to be used in more formal settings and contexts, in particular:

- in the series of Bologna Communiqués from Berlin 2003 onwards, when Ministers for the first time invited HEIs to adopt the Tuning approach in HE by using concepts and wording already developed within the Tuning community - even though the name Tuning was not explicitly mentioned;

- in several national or regional reform bills aimed at the implementation of the Bologna reforms, often adopting a language reflecting Tuning terminology and methodology; in some cases, such legislation referred to the Dublin Descriptors, which entered the Bergen 2005 Communiqué as a kind of "political" key word referring to the role of competencies and Learning Outcomes, i.e. to what the Tuning Community already used to call "reference points";

Over and above concepts and terminology, Tuning provided for the testing and use of concrete operational tools for the setting-up and management of the educational offer at the grass-root level within HEIs. These tools were mainly:

- A clear, simple and "operational" approach to what is meant by "competences" (what is left in the learner's brain and hands after completion of the educational process) and "Learning Outcomes" (what academics state at the planning stage of a degree programme as the desired outcomes of the learning process). Tuning has spread a pragmatic approach to these two core concepts, giving transparency to much of the literature existing on them and promoting in a workable way their inclusion in the educational debate and the practice of HEIs;

- The consultation of stakeholders and the links with the job market: this tool was based on a reasoned list of about 30 generic competences (grouped into Instrumental, Interpersonal and Systemic ones), which through the consultation of different stakeholders were to be rated according to their importance in the job market and to their degree of achievement through the educational process. The stakeholder groups included students, graduates, academics and employers. The source questionnaires, data gathering process and analysis method used are still available and applied in several circumstances;

- The Tuning list ${ }^{4}$ of key questions for planning/revising a degree programme: this seems to have been a particularly useful tool both as

${ }^{4}$ See: Julia González and Robert Wagenaar, eds., Tuning Educational Structures in Europe. Universities' Contribution to the Bologna Process. An Introduction. 2nd ed. (Bilbao: Universidad de Deusto, 2008), 135 (Annex 1). 
a synthesis of the operational steps of the Tuning overall methodology and as an inspiration for various types of quality enhancement processes;

- The "Tuning Reference Points" for more than 40 different Subject Areas: as already highlighted above, these are the pillars of the new methodology; the concrete identification of "reference points" in many different subject areas demonstrated the soundness and feasibility of the Tuning approach and served as a source of inspiration for its extension to other subject areas;

- Guidelines for the degree-profile description: this tool links both competences and learning outcomes directly to the programme, introducing in a clear manner the (new) concept of Programme Learning Outcomes. The guidelines ${ }^{5}$ also provide simple and concrete suggestions about how to structure the description of the relevant competences and Learning Outcomes;

- A fresh look at collection of student data, which increasingly focuses on gathering information about the students' "human" assets, expressed in terms of generic and subject specific competences in several contexts, including (but not limited to) the "assets" for graduates' access to the job market.

\section{Tuning as a "living" red thread through higher education programming}

Tuning Europe can also be looked at as being a kind of "living" red thread, which interweaves several different projects, causing the Tuning community to evolve and enrich itself with new perspectives and concepts. A conservative estimate suggests that representatives and experts from more than 600 European HEIs were actively involved. This can best be illustrated by recalling that each of the Tuning Brochures, which provide a synthesis of the best fruits of Tuning in as many as 43 different subject areas, was produced by a team of (on average) 15 subject area experts: 43 times 15 yields 645 experts.

The following table shows the sequence of projects and phases of the Tuning process in Europe (first column) and the main concepts and tools (second column) and other relevant developments (third column) of each project/phase.

${ }^{5}$ Jenneke Lokhoff, Bas Wegewijs, Katja Durkin, Robert Wagenaar, Julia González, Ann Katherine Isaacs, Luigi F. Donà dalle Rose, and Mary Gobbi, eds., A Guide to Formulating Degree Programme Profiles (Bilbao, Groningen, and The Hague: Universidad de Deusto, 2010). 


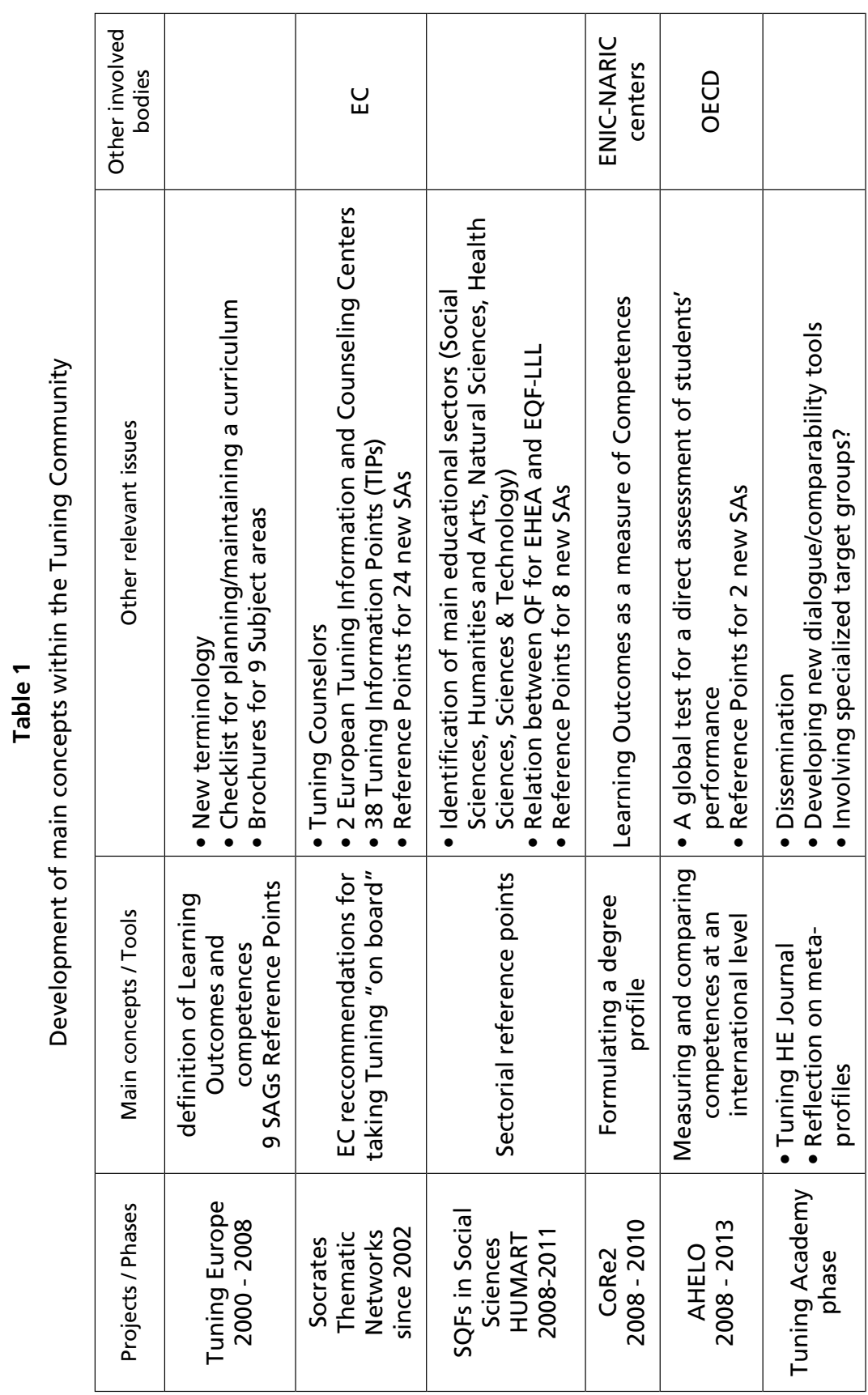


The first project - Tuning Educational Structures in Europe or simply Tuning Europe - was actually articulated in four two-year phases (or subprojects) and served as a real academic laboratory that produced new concepts and ideas and changed the way of thinking of many participating academics. Its main achievement was the development of a common and shared methodology (together with the corresponding terminology) about how to plan or update a degree programme, on the basis of a student-centred approach and of concepts like student sustainable workload (measured in ECTS), inventory of teaching/learning methods and of assessment habits. The objective of degree programmes is that at the end of the educational process each learner achieves well-defined "Learning Outcomes", through which she/ he acquires competences useful for her/his future life (both personal and professional). The Learning Outcomes - both at programme and course unit level - are defined in advance by the academics concerned, through a constructive dialogue/debate among themselves and with the interested outer world. At the same time, "competences" are seen as an asset of each individual student, once she/he has successfully completed the whole programme.

This first project showed the feasibility of the whole Tuning methodology and yielded inspiring fruits in nine Subject Areas: seven of these (Business, Chemistry, Education Sciences, Earth Sciences, History, Mathematics and Physics) participated in the initial project, and two more (Nursing, a regulated degree programme, and European studies, an interdisciplinary programme) joined half way. Most of these Subject Area Groups (SAGs in the Tuning jargon) were backed by already existing Socrates Thematic Network Projects (TNPs). Already at that time it became clear that going through the Tuning methodological process in a "second run", relying on the experience of the TNP, was much more effective and less time consuming. This observation was confirmed by all subsequent work, both in and outside Europe. The final "deliverable" of the Tuning Europe project was a set of nine Tuning Brochures providing the Tuning key concepts and, for each subject area, a list of relevant intended Learning Outcomes and of generic as well as subject specific competences; these lists became known as "Tuning Reference Points".

The second important step in the European Tuning process started in 2002 when the European Commission recommended to all Socrates TNPs - about 35 at that time - to "take Tuning on board" in their own Project. This led to new interesting developments, in parallel to the on-going Tuning Europe project. Some Tuning Europe participants became Tuning counsellors coaching one or more TNPs. This paved the way for the subsequent establishment of 2 European Tuning Information and Counselling Centres and of 38 national Tuning Information Points (TIPs). This led to the production of Tuning Brochures for 24 additional subject areas. 
A third stage of Tuning started in 2008 when Tuning proposed to prepare Sectorial Qualifications frameworks ( $S Q F)$ as a contribution to the debate on the European Qualification Frameworks, i.e. the EQF for the European Higher Education Area already adopted in 2005 as part of the Bologna Process, and the broader EQF for Lifelong Learning encompassing all types and levels of qualifications. Developing such "Sectorial" Qualification Frameworks consisted mainly in identifying Tuning Reference Points common to a broad "sector" of related subject areas. Five sectors were identified: Social Sciences, Humanities and Arts, Natural Sciences, Health Sciences, Sciences \& Technology. In the end, two SQF projects were funded, respectively for Social Sciences and for Humanities and fine Arts ("HUMART"). They yielded Tuning Reference Points and Tuning Brochures in eight additional areas: International Relations, Law, Psychology, Social Work (for the SQF in Social Sciences ${ }^{6}$ ), Art History, Literary Studies, Linguistics, and Theology/Religious Studies (for the HUMART SQF ${ }^{7}$ ).

Tuning was also involved in two other projects: CoRe2 (Competences in Education and Recognition - phase 2), led by the NARIC network, produced guidelines for the description of programme profiles (in terms of Learning Outcomes and the development of the related competences); the OECD-led AHELO (Assessment of HE Learning Outcomes) project aims to develop a global test assessing the performance of HE students in Economics and Engineering and comparing them on a worldwide scale using Tuning Reference Points for each subject area and for generic skills. This led to the preparation of innovative tools for student assessment and further contributed to the series of Tuning Brochures. The final outcomes of AHELO are expected later in $2013,{ }^{8}$ but it seems already clear from the case of Engineering that they will resemble Tuning's new way of looking at competences, called a "meta-profile" (see next paragraph).

The hitherto final stage of Tuning Europe is the Tuning Academy, which was announced in 2008 and formally launched in 2011. It has added two important new developments: the regular publication of the Tuning Journal

${ }^{6}$ Julia González, "Tuning Sectoral Framework for Social Sciences. Final Report, Public Part." Education, Audiovisual \& Culture Executive Agency of the European Commission, 2008. http://www.unideusto.org/tuningeu/images/stories/sectoral_framework/2007_10347_ FR_Tuning_SQF_PUBLIC_PART.pdf.

7 Tuning Project,Tuning Sectoral Qualifications Frameworks for the Humanities and the Arts. Final Report 2010 - 2011 (Bilbao: University of Deusto, 2012).

${ }_{8}$ While waiting for the final reports, see Organisation for Economic Co-operation and Development (OECD), "Higher Education and Adult Learning. Testing Student and University Performance Globally: OECD's AHELO,” OECD, http://www.oecd.org/education/ highereducationandadultlearning/testingstudentanduniversityperformancegloballyoecdsahelo.htm. 
in Higher Education (TJHE), aimed at disseminating TUNING contributions and coaching new generations of Tuning "followers"; and the development of the meta-profile concept, which adds new light to the Tuning Reference Points. A meta-profile aims at making explicit the relationship and hierarchy among competences in a given subject area; the earlier lists of generic and subject-specific competences are merged into a reasoned structure of competences. The meta-profile includes innovative competences as a source of inspiration for concrete programme (re)- planning in the given subject area. This new concept has already facilitated and enriched the dialogue between European Tuning Community and Tuning processes elsewhere in the world (notably Latin America, Russia and Africa), where the coverage of subject areas tends to be similar to the European ones, but always with a novelty, originality and freshness specific to each region.

An overview of the 43 subject areas for which Tuning Europe produced teaching/learning reference points is shown in Table 3 (Section III).

\section{Tuning Europe at work: some examples}

The examples that follow were chosen from Thematic Network Projects drawing on the Tuning approach and on the collaboration with Tuning experts. It was already mentioned that the effectiveness and efficiency of the Tuning method was enhanced in areas where a first round of discussion could be organised within the framework of the TNP, and over 55\% of all Tuning Reference Points in Europe were produced in cooperation with a TNP. These examples are meant to show the flexibility, pragmatism and richness of the Tuning perspective.

- Arts and Music: Tuning cooperated with the European League of Institutes of the Arts $\left(\mathrm{ELIA}^{9}\right)$ in a sequence of 3 TNPs; this extensive work led to a handbook ${ }^{10}$ containing four Tuning documents in the areas of dance, design, fine art and theatre; later on, a similar document dealing with film/screen arts was also produced. These documents cover all three cycles, with advanced insights on the doctoral cycle - even though a common European approach and format is still seldom at this

${ }^{9}$ European League of Institutes of the Arts (ELIA), "Tuning Document for Film/Screen Arts Education," EIA, http://www.elia-artschools.org/images/activiteiten/20/files/Tuning\%20 document $\% 20$ film $\% 20$ EN.pdf.

${ }^{10}$ John Butler, Kieran Corcoran, Tomasz Kubikowski, and Truus Ophuysen, eds., Tapping into the Potential of Higher Arts Education in Europe, Interartes Handbook (Amsterdam / Warsaw: European League of Institutes of the Arts (ELIA), 2008). 
level. Tuning also cooperated with the Association of European Conservatories (AEC) through a TNP called Polifonia ${ }^{11}$ that was set up as a 'Tuning' Working Group. Its main objective was to develop the existing AEC descriptions of learning outcomes for the 1st and 2nd cycles to the next level of sophistication and implementation, by linking learning outcomes with other dimensions, such as: the relation with competences, the use of credit points, competence-based teaching and learning, assessment procedures, curriculum design in modular systems, internal and external quality assurance mechanisms, etc." Several deliverables were produced: three handbooks for higher music education, reference points and sectorial Dublin Descriptors, a pool of Tuning counsellors in the area of Music, etc. The success of the Tuning methodology in the areas of Arts and Music may have been eased by the attention paid in these areas to students' performance, which is intrinsic to any artistic teaching/learning effort; yet, the Tuning approach helped HEIs in Arts and Music to connect with the broader EHAE community, not least thanks to Bologna experts who were also Tuning experts.

- Occupational Therapy: this area saw a joint "success story" between Tuning and the two existing TNPs (one between national associations of professionals in Occupational Therapy, and the other between academics from some 170 HEIs offering qualifications in OT). The process started with an extensive consultation of students, teachers and practitioners about Generic and Subject Specific Competences. The application of the Tuning methodology led to an in-depth review or the creation of degree-courses in several countries in the EU (notably the UK) and elsewhere (Turkey, Armenia, Georgia).

- Humanitarian Development Studies: the adoption of the Tuning methodology allowed the TNP to (re)shape three international master courses (including an Erasmus Mundus Master), define two "Tuning planned" international doctoral programmes (on Migration \& Diversity and Peace \& Conflict Studies) and establish a Sectorial Qualifications Framework in the subject area.

\section{Assessment of the contribution of Tuning to key aspects of the EHEA}

This section tries to provide an assessment of Tuning's contributions to the setting up of the European Higher Education Area. This may be done

${ }^{11}$ ERASMUS Network for Music 'Polifonia', http://www.polifonia-tn.org/. 
from various perspectives; one is to look at the quantitative impact on the academic community and the academic study areas; another one is to review from a qualitative viewpoint the contribution of Tuning to the implementation of the joint Bologna-Lisbon change agenda on which Tuning has impacted.

\section{The Tuning tools have a very strong impact on the academic community}

A simple e-way to measure it is to look at the hits on the various regional Tuning websites. Table 2 below shows the absolute number of hits corresponding to the websites of the main Tuning processes set up so far, i.e. Tuning Europe, Tuning Latin America 1 and 2, Tuning Africa and Tuning Russia.

Table 2

Regional Tuning websites: absolute number and growth rate of hits

\begin{tabular}{|l|c|c|c|}
\hline \multicolumn{1}{|c|}{ Web page } & $\begin{array}{c}\text { Number of hits } \\
\text { (checked 17 } \\
\text { November 2012) }\end{array}$ & $\begin{array}{c}\text { Growth rate } \\
\text { (hits/day) } \\
\text { (november 7th } \\
\text { to 17th, 2012) }\end{array}$ & $\begin{array}{c}\text { Starting date of } \\
\text { the web site }\end{array}$ \\
\hline $\begin{array}{l}\text { Tuning Europe } \\
\text { http://www.unideusto.org/tuningeu/ }\end{array}$ & 4.236 .231 & 425 & $\begin{array}{c}\text { December } \\
2004\end{array}$ \\
\hline $\begin{array}{l}\text { Tuning LA (1st) } \\
\text { http://tuning.unideusto.org/tuningal/ }\end{array}$ & 5.124 .990 & 813 & $\begin{array}{c}\text { September } \\
2004\end{array}$ \\
\hline $\begin{array}{l}\text { Tuning LA (2nd) } \\
\text { http://www.tuningal.org/ }\end{array}$ & 290.889 & 799 & $\begin{array}{c}\text { February } \\
2011\end{array}$ \\
\hline $\begin{array}{l}\text { Tuning Africa } \\
\text { http://www.tuningafrica.org/ }\end{array}$ & 113.129 & 325 & $\begin{array}{c}\text { November } \\
2011\end{array}$ \\
\hline $\begin{array}{l}\text { Tuning Russia } \\
\text { http://www.tuningrussia.org/ }\end{array}$ & 133.263 & 708 & $\begin{array}{c}\text { February } \\
2011\end{array}$ \\
\hline
\end{tabular}

These figures should be interpreted recalling that the actual number of hits depends on the date at which the various websites became active (rather recently in the case of some non-European versions of Tuning). It also depends - in a more complex manner - on the academic community involved and on the possible search operations in different geographical areas. It is also interesting to look at the growth rate of these hits, in terms of hits/day. The Table shows that in November 2012 Tuning Europe counted 4.2 million hits, with a growth rate of 425 hits/day. The strong interest of the academic communities backing Tuning 
Latin America, Tuning Russia and Tuning Africa is also reflected in the impressive growth rates of hits/day in these regions (in particular in Africa, bearing in mind the difficult technological context in some regions).

Another way to assess the contribution of Tuning Europe to the profiling of higher education programmes is to look at the list of subject areas covered. Table 3 provides an overview of the 43 subject areas for which there are Tuning Reference Points and shows by which particular Tuning project they were produced (or co-produced, in the case of collaboration with TNPs or other co-operative Projects ${ }^{12}$ ).

\section{Impact of Tuning on key dimensions of the higher education reforms in Europe}

Unsurprisingly, Tuning's strongest and most direct impact on European higher education reforms is to be found in the area of curricular change, modernisation of teaching/learning and programme renovation/profiling. The quantitative data provided in the tables 2 and 3 refer mainly to this "direct" contribution to the enhancement of programme quality and relevance. ${ }^{13}$ It can be found in all subject areas (even in those not explicitly covered by a specific set of "Tuning Reference Points"), at all levels (first degree, Master, but also Doctorate) and at all various types of HEIs in all various participating countries. There is no doubt that Tuning - and its shared terminology - had a wide "multiplier effect" reaching far beyond the direct circle of participating academics and institutions.

As was mentioned already, Tuning has contributed to making the Bologna/Lisbon calls for curricular change more understandable and more concrete. It may well be that, while restructuring the architecture of degrees was already perceived as a difficult enough exercise, the Tuning call to add such in-depth curricular and methodological change may have pushed-up the hurdles on the way to modernisation beyond the immediate reach of some actors and institutions. But this was necessary for an effective implementation of the Bologna action lines and Lisbon agenda for university modernisation.

This does of course not mean that the Tuning methodology was always applied correctly, completely and wisely. The same as the Bologna Process itself, the Tuning principles were sometimes misunderstood or distorted and

${ }^{12}$ For an almost exhaustive list of Tuning Europe subject areas, see http://www.unideusto. org/tuningeu/subject-areas.html

13 Julia González and Robert Wagenaar, Tuning Educational Structures in Europe. Universities' Contribution to the Bologna Process, 111. 


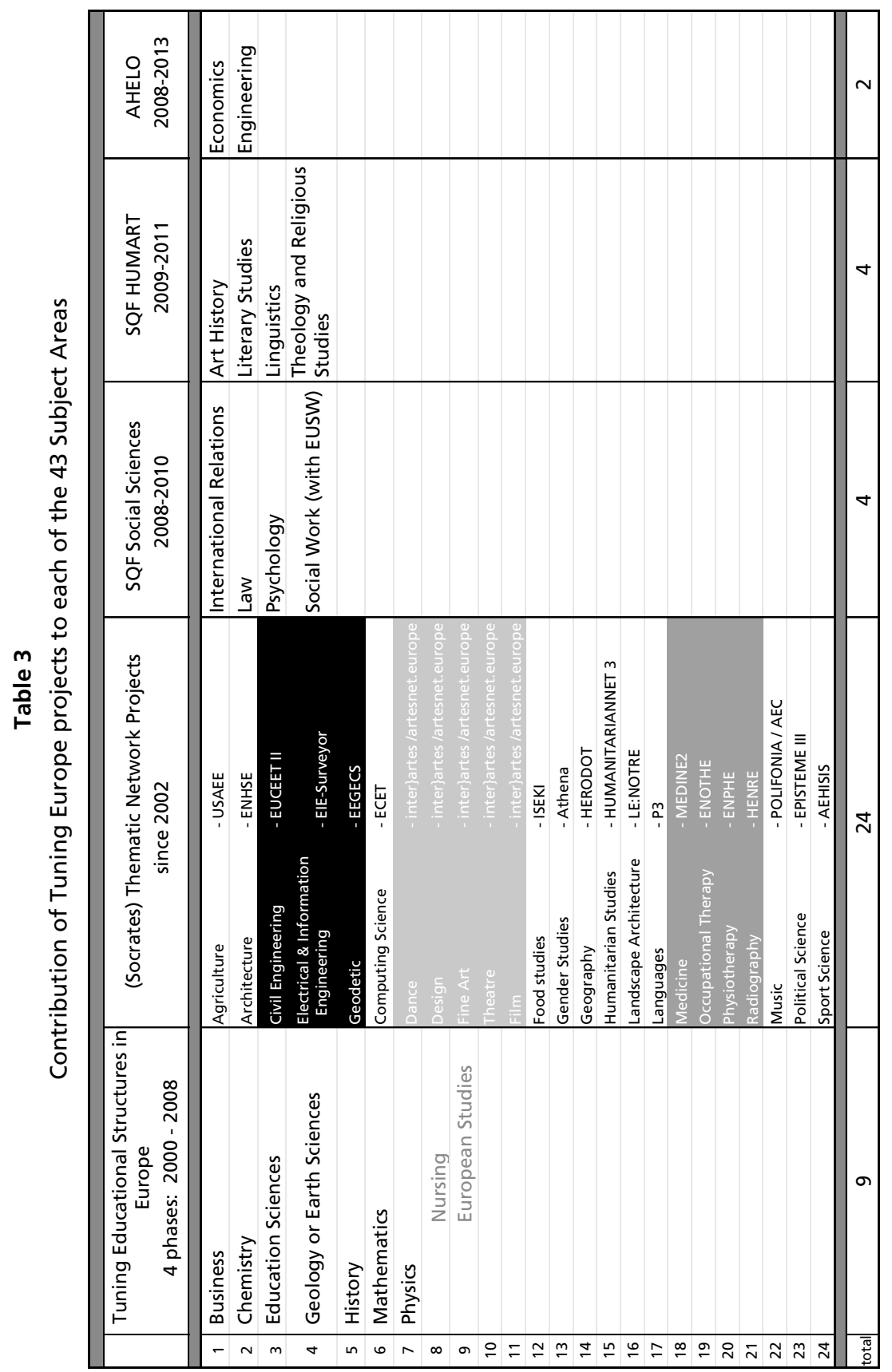


used as an excuse to push reforms into directions suiting certain vested interest. As with Bologna, Tuning was sometimes resisted because it allegedly may impose more "uniformity" (if all HEIs in the end offered very similar programmes geared towards the same Reference Points), while both Bologna and Tuning have been geared towards creating convergence on certain key aspects, and at the same time diversifying ("profiling") programmes in view of their different contexts, aims and institutional/ national settings. Bologna and Tuning have always shown the greatest respect for such cultural, national/regional, systemic and institutional differences, but not all actors have been able (or willing) to look at the inevitable tension between the creation of enough convergence and the need for more differentiation.

The same as with the Bologna instruments, the Tuning tools were on occasions applied as if they were to be simply replicated, while they are mainly an invitation to think and find an appropriate answer in the case of each programme at each HEI, depending on the socio-cultural and socioeconomic context, the programme's audience and objectives, and the HEIs mission and profile. This means that not all academics have always used the Tuning approach to its full capacity, and that a number of opportunities to renovate and differentiate programmes in a sensible and effective way have been missed.

It should also be acknowledged that the renovation and profiling of programmes according to the Tuning (and Bologna/Lisbon) principles tends to be introduced in incremental stages, not always in a single, strategic move. But there is not the least doubt that Tuning, backed by Bologna and the Lisbon agenda, has been a crucial factor for the renovation of teaching/ learning programmes and methods at higher education institutions in Europe.

This also means that Tuning has contributed to enhancing the overall "quality" of the educational programmes offered by European HEIs, in particular with respect to their relevance to the needs of society and of learners. By emphasizing that learners should learn that which will help them in their personal and professional life, Tuning has broken a certain academic tradition focused on encyclopaedic knowledge restricted to a specific subject area. By stressing the importance of Lifelong Learning, it has contributed to breaking the model of overlong initial education programmes that has prevailed in some countries. By insisting on the importance of transversal and generic competences, it has contributed to multi-disciplinarity and to enriching the qualification and professional perspectives of thousands of graduates. From this viewpoint, it may be correct to say that the strongest impact of Tuning on higher education programmes is that it has enhanced their socio-economic relevance - more than their purely academic "quality". 
Making programmes more transparent by gearing them towards explicitly stated objectives (Learning Outcomes formulated in terms of competences) also creates, ipso facto, more transparency and hence facilitates the recognition of qualifications across institutional or national boundaries. While it is probably impossible to measure its impact on this important dimension of the EHEA, it seems certain that Tuning has contributed extensively to easing the mutual recognition of credits and full qualifications, thanks to their better understanding at other HEIs. The same applies to the recognition of competences or qualifications by employers, once they are clearly stated in terms of LOs and guaranteed levels of skills/competences. Easier recognition contributes to easier/freer mobility - even though the actual level of mobility also depends on many other factors.

Tuning has also made an important - albeit less direct, less visible and less emphasised - contribution to another core dimension of the EHEA, in the area of quality assurance and quality certification. While emphasizing the key role of universities themselves in guaranteeing and improving their "quality" ("internal" quality assurance), the Bologna Process and the EU's Agenda for the Modernisation of Higher Education have encouraged a system of "external" quality assurance based mainly on national agencies; these agencies are of very diverse types and carry out various different tasks, reaching from broad "quality audits" to minute "programme accreditation"; although many agencies use the European Standards \& Guidelines for quality assurance (ESG) as a common reference, their actual implementations (i.e. the criteria, procedures and level of requirement) may vary substantially from one country to another. While some more convergence between national agencies may happen in the years ahead, the architecture of the current QA system of Europe could be significantly consolidated thanks to a second pillar not based on national approaches, but on European-wide quality seals in specific subject areas (or qualifications sectors). This was acknowledged in the most recent Progress Report in QA in higher education in Europe. ${ }^{14}$ Some examples of European seals of quality already exist (e.g. EQUIS in Management studies or the Chemistry Quality Eurolabels ${ }^{15}$ ) and others are in development (like EURACE in Engineering or EUR-INF in Informatics) and some new similar initiatives have started, e.g. in Music. There is absolutely no doubt that

${ }^{14}$ Commission of the European Communities, "Report on Progress in Quality Assurance in Higher Education." Report from the Commission to the Council, the European Parliament, the European Economic and Social Committee and the Committee of the Regions, COM(2009) 487 final (Brussels: European Union, 2009).

15 The EuroBachelor quality label was a very concrete outcome produced by the TNP European Chemistry Thematic Network within Tuning Europe (2004). 
Tuning's Europe-wide, comparative and subject-based approach has contributed to the development of some of these European quality seals and has the potential to underpin the development of many more in the future.

These remarks are but a brief review of Tuning's many contributions to the EHEA. They show that the Tuning "vision" of the year 2000 has become a highly creative and interactive process and a powerful mover in higher education, first in Europe and soon after in other world regions. After 12 years of growth and dissemination, the experience gained by the "Tuning processes" around the world has started "coming back" to Europe and is now enriching the much-needed debate about the role and competitiveness of European higher education in the world. This became very clear at "Tuning in the World" event in Brussels in November 2012. More refined tools are being developed and new priorities are being identified.

This also means that new challenges will need to be addressed:

- new target groups: should Tuning specifically address degree programme planners on the basis of new concepts, like meta-profiles?

- new dissemination tools: should there be a wider effort to spread the Tuning approach amongst all actors involved at grass-root level (academics, administrators, managers, policy makers)? Should transversal skills related to citizenship, social commitment and ethical behaviour be promoted as a core ingredient of all programmes?

- new processes: should recognition procedures (e.g. for study abroad, prior learning, etc.) and corresponding QA procedures based on Learning Outcomes and competences be tested in some broad, European-wide, pilot projects?

These questions show that while Tuning has already substantially contributed to quality, relevance and innovation in the EHEA, it has the potential to continue doing so in the years ahead, which are likely to be marked by accelerated reforms required by the Knowledge era and the worldwide competition in higher education.

\section{Bibliography}

Butler, John, Kieran Corcoran, Tomasz Kubikowski, and Truus Ophuysen, eds. Tapping into the Potential of Higher Arts Education in Europe, InterArtes Handbook. Amsterdam / Warsaw: European League of Institutes of the Arts (ELIA), 2008.

Commission of the European Communities. "Delivering on the Modernisation Agenda for Universities: Education, Research, and Innovation." Communication 
from the Commission, $\operatorname{COM}(2006) 208$ final, 16. Brussels: European Union, 2006. http://ec.europa.eu/euraxess/pdf/COM(2006)_208.pdf.

"Mobilising the Brainpower of Europe: Enabling Universities to Make Their Full Contribution to the Lisbon Strategy." Communication from the Commission, COM (2005) 152 final, 12. Brussels: European Union, 2005. http://ec.europa.eu/ education/policies/2010/doc/comuniv2005_en.pdf.

- "Report on Progress in Quality Assurance in Higher Education." Report from the Commission to the Council, the European Parliament, the European Economic and Social Committee and the Committee of the Regions, COM(2009) 487 final, 11. Brussels: European Union, 2009. http://ec.europa.eu/education/ higher-education/doc/report09_en.pdf.

ERASMUS Network for Music 'Polifonia'. http://www.polifonia-tn.org/.

European League of Institutes of the Arts (ELIA). "Tuning Document for Film/ Screen Arts Education." EIA, http://www.elia-artschools.org/images/ activiteiten/20/files/Tuning\%20document\%20film\%20EN.pdf.

González, Julia. "Tuning Sectoral Framework for Social Sciences. Final Report, Public Part." Education, Audiovisual \& Culture Executive Agency of the European Commission, 2008. http://www.unideusto.org/tuningeu/images/ stories/sectoral_framework/2007_10347_FR_Tuning_SQF_PUBLIC_PART. pdf.

González, Julia, and Robert Wagenaar, eds. Tuning Educational Structures in Europe. Universities' Contribution to the Bologna Process. An Introduction. 2nd ed. Bilbao: Universidad de Deusto, 2008.

Lokhoff, Jenneke, Bas Wegewijs, Katja Durkin, Robert Wagenaar, Julia González, Ann Katherine Isaacs, Luigi F. Donà dalle Rose, and Mary Gobbi, eds. A Guide to Formulating Degree Programme Profiles. Bilbao, Groningen, and The Hague: Universidad de Deusto, 2010.

Organisation for Economic Co-operation and Development (OECD). "Higher Education and Adult Learning. Testing Student and University Performance Globally: OECD's AHELO." OECD, http://www.oecd.org/education/ highereducationandadultlearning/testingstudentanduniversityperformance globallyoecdsahelo.htm.

Tuning Project. Tuning Sectoral Qualifications Frameworks for the Humanities and the Arts. Final Report 2010 - 2011. Bilbao: University of Deusto, 2012. 